\title{
Acquired unilateral loss of dark adaptation
}

\author{
J. H. KELSEY AND G. B. ARDEN \\ Moorfields Eye Hospital, City Road, London
}

Poor dark adaptation is a not uncommon symptom and may occur in a wide variety of diseases but its occurrence in one eye only is far less frequent. When it occurs unilaterally, an obvious ocular disease is generally present to account for it and visual functions other than that of dark adaptation are also depressed. Some subjects with poor dark adaptation may have no demonstrable ocular lesion nor any other defect of visual function. Almost always they have one of the forms of congenital night blindness but sometimes the trouble is the first evidence of a progressive tapeto-retinal degeneration. Electrophysiological studies of the retinal function of these patients have proved to be useful, and Armington and Schwab (1954) have shown that by using electroretinography patients with a non-progressive night blindness can be differentiated from those with a progressive tapeto-retinal degeneration. Auerbach, Godel, and Rowe (1969) have similarly studied a large series of patients with night blindness. They have shown that patients with an apparently stationary night blindness fall into two main groups, but they also note that progression of the condition may occur. An acquired form of night blindness without obvious ocular defects and without disturbance of any other ocular function was described by Kelsey and Arden (1969) in which electrophysiological tests of retinal function suggested a lesion at the level of the bipolar cell layer. Two patients with similar acquired changes which were strictly uniocular are described below.

\section{Methods}

Dark adaptometry was done using a Goldmann-Weekers Dark Adaptometer. Electro-oculography (EOG) was based on the technique described by Arden, Barrada, and Kelsey (1962), and electroretinography (ERG) was carried out in a manner similar to that described by Karpe (1945). The details of the methods have been described previously by Kelsey and Arden (1969).

\section{Case reports}

(I) A man aged 48 (MED 620) had complained of gradually worsening vision of the right eye for several months.

\section{EXAMINATION}

The unaided visual acuity was $6 / 12$ in the right eye and $6 / 18$ in the left. The refractive error was not determined but no ocular abnormality could be found. A tentative diagnosis of tobacco amblyopia was made and the patient was referred to the Electrodiagnostic Clinic for further investigation before a more detailed clinical evaluation was carried out. 
When he was seen in the Electrodiagnostic Clinic the visual fields were determined using a Goldmann Projection Perimeter. The left peripheral field was found to be full but there was a slight generalized constriction of the right field. No scotoma indicative of tobacco amblyopia could be found. The results of the other tests are shown in Fig. I.
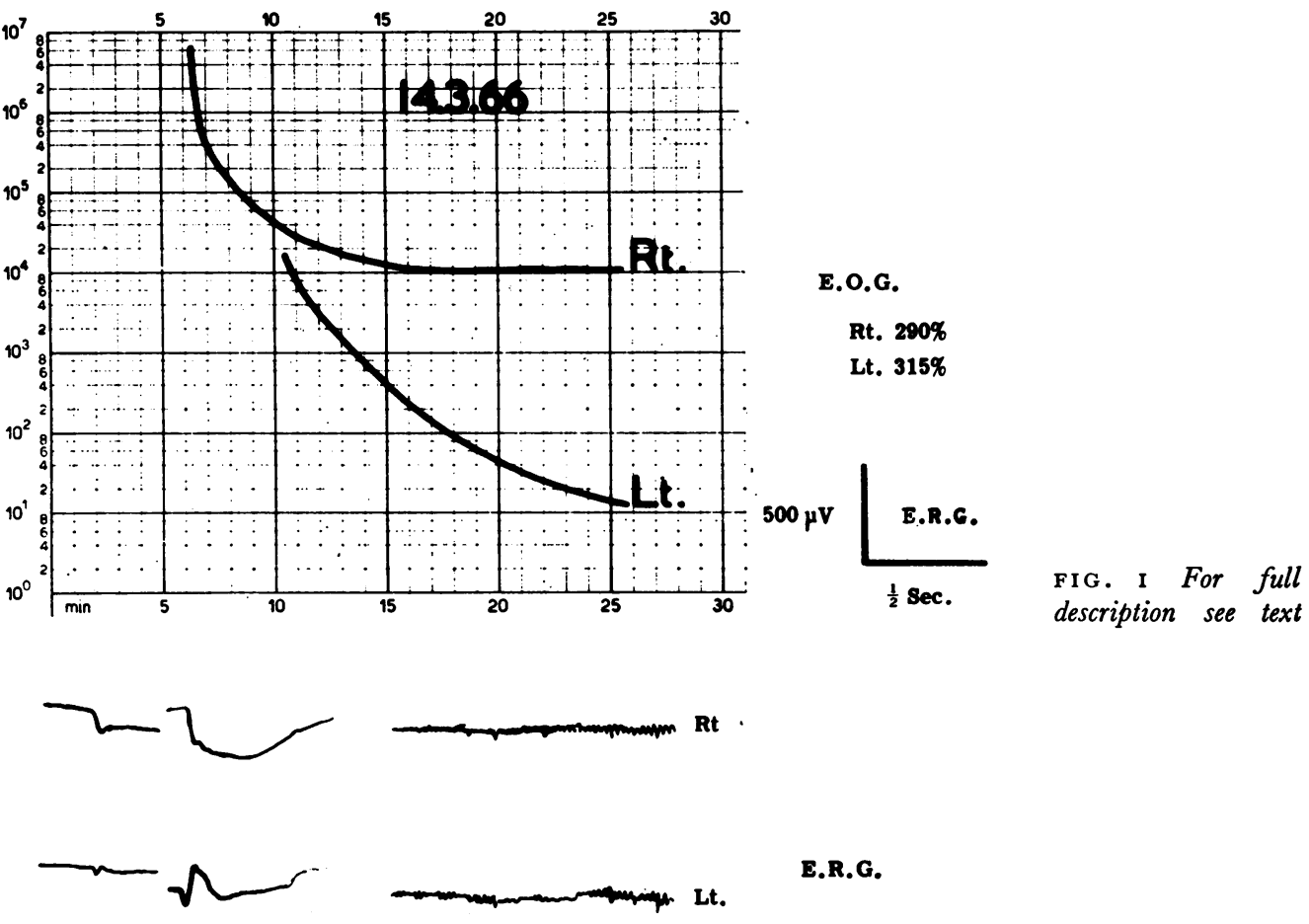

E.R.G.
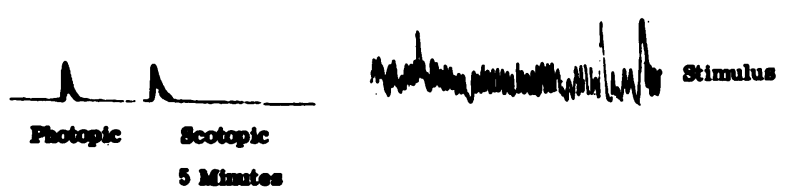

Dark adaptometry confirmed that the vision in the right eye was abnormal in that a scotopic phase was absent while the left eye had a normal curve. The EOG showed a normal response in both eyes with a light rise of 290 per cent. from the right eye and of 315 per cent. from the left eye. The left ERG was normal. The right ERG was abnormal in that only a negative potential was recorded which returned to the baseline after 0.5 to I second. The flicker fusion rate of the two eyes was normal.

After these tests the patient failed to return to the outpatient clinic and postal enquiry has failed to elicit his whereabouts.

(2) A married lady aged 50 (MED I I4I) in good health had had no eye trouble before the onset of her present complaint. One night she awoke and noticed that the vision of the right eye was abnormal. The bedroom was dimly lit by a light outside, and with her left eye she was able to discern the objects in the room but with her right eye she could see none of them. With the right eye she could see the light outside but it seemed to have an orange hue. Enquiry revealed no 
possible precipitating cause of this visual change. She was on no systemic medication and the only unusual recent event had been that she had cleaned a boat with an organic solvent a day or so previously.

\section{EXAMINATION}

No ocular abnormality could be found on clinical examination. There was a minimal refractive error and the visual acuity was $6 / 6$ in each eye. The ocular media were clear and apart from a non-specific pigmentary mottling of the periphery the fundi were normal. The visual fields to $3 / 300$ on the Lister perimeter and 2/2,000 red and white on the Bjerrum screen were full and equal in the two eyes.

The patient was seen in the Electrodiagnostic Clinic on July 27, 1967, and the results are shown in Fig. 2. The subjective change in dark adaptation was confirmed by the absence of a scotopic phase in the right eye while the left eye had a normal curve. The EOG of the left eye had a normal light rise of 200 per cent., but that of the right eye was subnormal at 145 per cent. The ERG of the left eye was normal but that of the right eye had a negative deflection only. The flicker fusion response was technically unsatisfactory but no abnormality was evident in either eye.

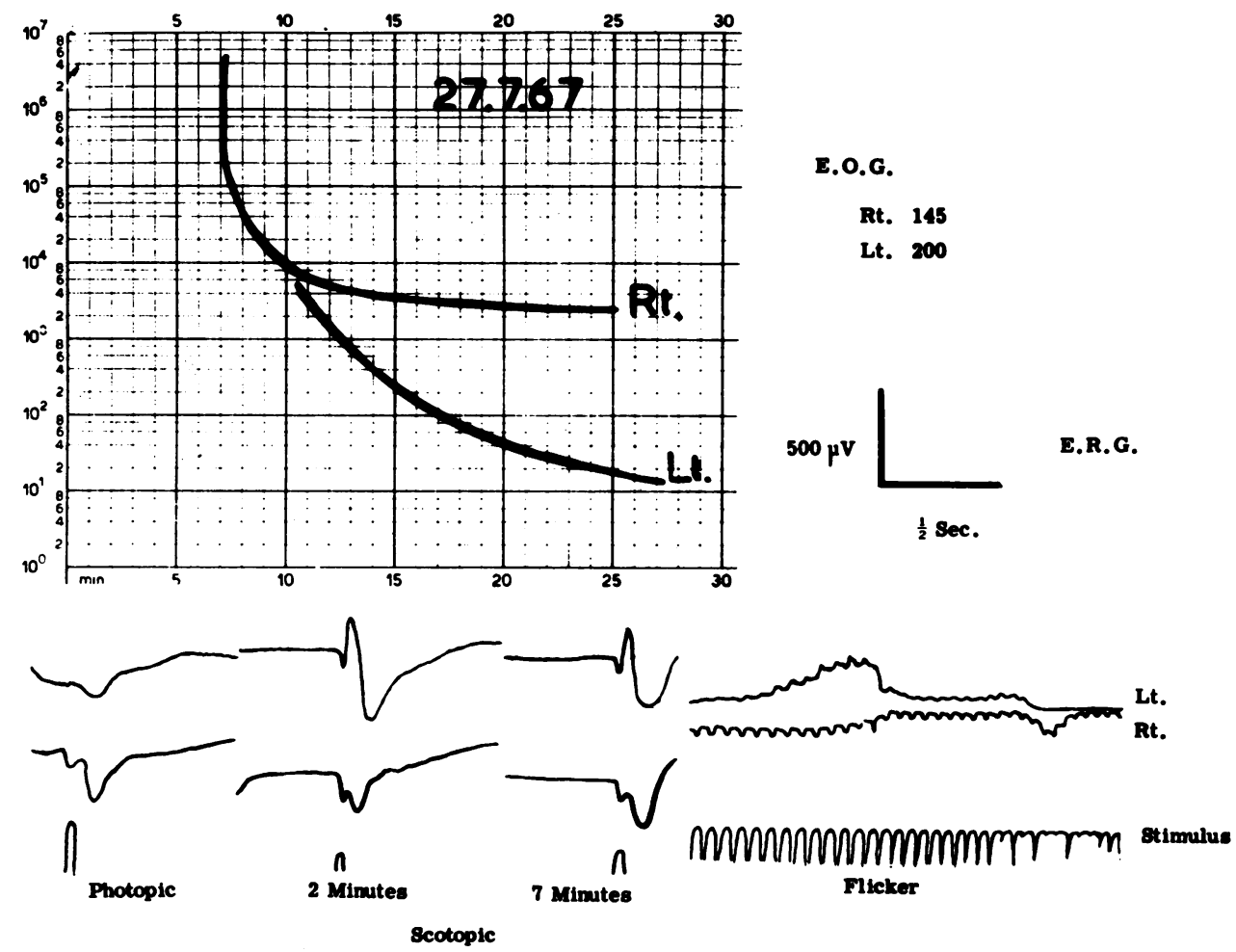

FIG. 2 For full description see text

The patient's condition remained unchanged for 4 months when she reported that the vision of the right eye had returned suddenly to normal. The electrodiagnostic tests were repeated on November 9, 1967, and the results shown in Fig. 3 (opposite) confirmed the symptomatic recovery. All the results were normal and equal in the two eyes.

Enquiry 2 years later has revealed that the condition has not recurred. 


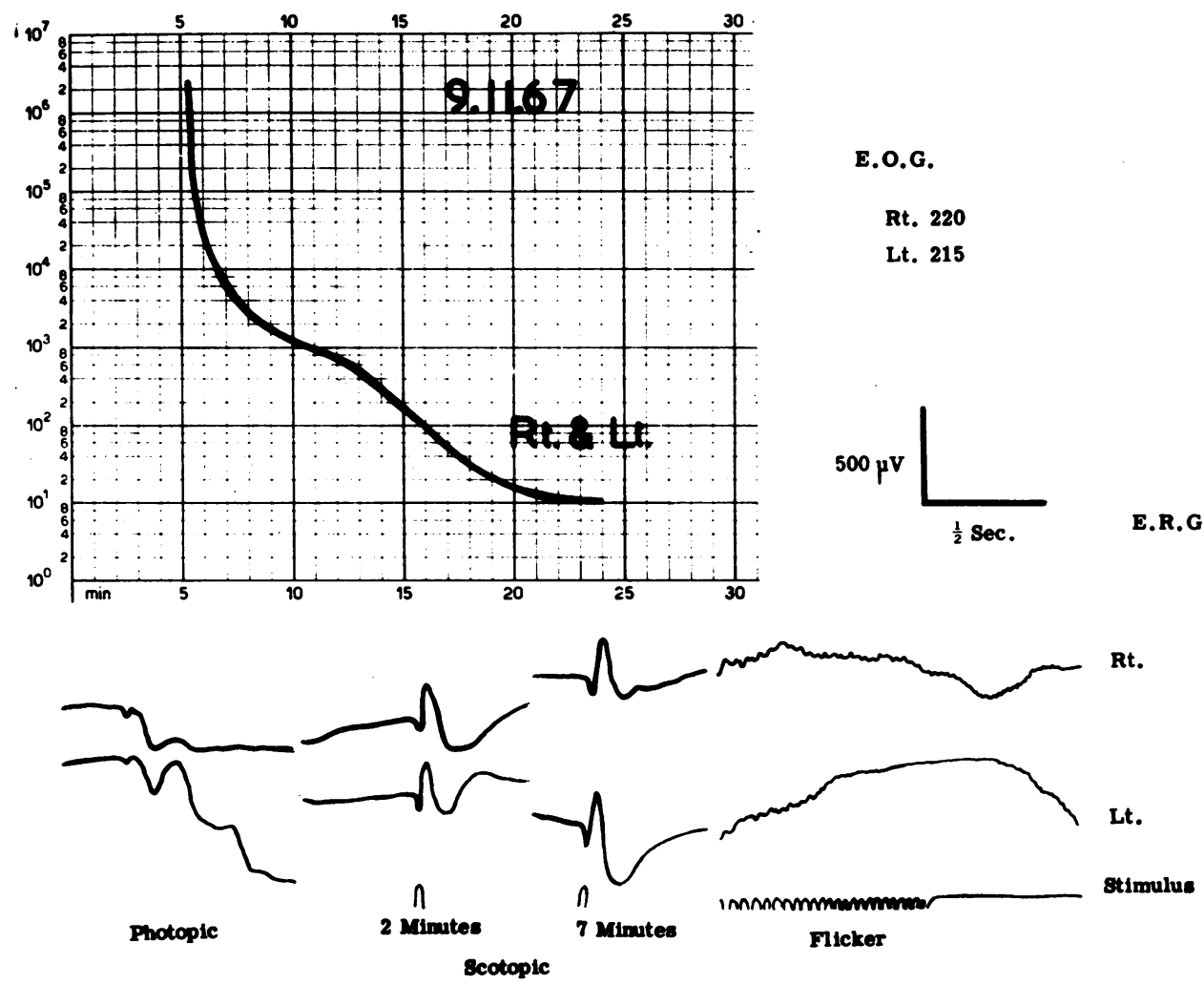

FIG. 3 For full description see text

\section{Discussion}

The mechanism of dark adaptation is still uncertain, but Arden and Weale (1954) have demonstrated that a nervous process is involved and Dowling (1967) has suggested that this process occurs at the level of the bipolar cells. Thus the use of both the EOG and the ERG might be expected to be of use in the investigation of abnormalities of dark adaptation, as it is probable that the EOG arises from the external retinal layers (Arden and Kelsey, 1962) while the ERG has a contribution from the bipolar cell layer (Brown, 1966).

Animal studies cannot be expected to show the relation of electrophysiological changes to dark adaptation as the visual function is highly subjective, but two papers are relevant to this discussion. Cone and Ebrey (1965) occluded the central retinal artery of the rat and produced an ERG of the receptor potential waveform similar to that of the patients described. Unlike our patients the flicker fusion of the receptor potential of the rat was abnormal in that it failed to follow a stimulus that could be followed by the ERG of the intact rat.

It seems unlikely that the lesion causing the trouble in our patients is equivalent to a blockage of the central retinal artery. This supposition is supported by the findings of Gouras and Carr (1965), who occluded the central retinal artery of the monkey. Here again a receptor potential type of ERG was produced, but it was noted also that the EOG 
was lost. This the authors took as evidence against the theory of the origin of the EOG from the outer layers of the retina and they suggested that it must arise from a level similar to that of the ERG $b$-wave. Clinical evidence in humans and the histological preparations of the authors show that the effect of the central retinal artery block is not confined to its $\overrightarrow{\vec{D}}$ level of supply and an externally originating EOG could easily be disturbed.

Several cases of central retinal artery occlusion have been seen in this clinic. The $\frac{\overline{0}}{\bar{D}}$ patients have usually been in the acute phase of the condition, and it was found that both $\frac{\bar{\sigma}}{\vec{D}}$ the EOG and the ERG were grossly deranged. This may be expected both from the $\stackrel{\mathbb{}}{\circ}$ extensive retinal disturbance seen ophthalmoscopically which gives a picture quite unlike that found in our patients and from the possibility that the block also affects the choroidal $\vec{\circ}$ circulation. One patient with an optic atrophy due to an old retinal artery occlusion has been seen in the clinic who had the typical negative ERG in the affected eye with a normal ERG in the unaffected eye and a normal EOG in both eyes. Unfortunately this patient was seen in the early days of the clinic and the flicker fusion test was not performed. That $f$ the dark adaptation was not tested was probably due to the fact that the visual acuity in $\overrightarrow{\mathrm{c}}$ this case was perception of light.

Glinical studies of night-blind patients using both the ERG and the EOG have been infrequent. Carr, Ripps, Siegel, and Weale (1966) described a night-blind female who $\vec{c}$ had been shown to have a normal retinal concentration of rhodopsin. She had a negative ERG and the authors suggested that the abnormality causing the poor night vision lay at the level of the bipolar cells. She had a low EOG and in the presence of a normal retinal concentration of rhodopsin it was considered that the EOG could not arise in the external retinal layers. Like Gouras and Carr (1965) these authors proposed an origin proximal to the retinal receptors. This may not be a valid proposal as their patient was shortsighted and it has been shown that myopes tend to have a low EOG (Barrada and Kelsey, 1964).

There is therefore good evidence that poor night vision may be caused by a defect at the $\stackrel{\varnothing}{\mathbb{D}}$ level of the bipolar cell layer. It is probable that there are several causes for this, giving rise to congenital, juvenile acquired, and adult acquired forms. Furthermore, it seems that irreversible cell damage may not occur as recovery can take place. The change in the EOG in the night-blind period of the patient who recovered is difficult to explain, and it is unfortunate that this test was not done at intervals while she was affected by night $O$ blindness. The first test was done at the onset of the condition. Experience in this clinic has shown that the EOG is the most sensitive of all the electrophysiological tests to any generalized retinal abnormality and the result may be merely an expression of this general rule. Arden (1968) has also suggested that a change in the EOG may take place $\frac{\text { o }}{9}$ because of a lesion of the more proximal retinal layers without the EOG generator being $\rightarrow$ directly affected.

Whatever the cause of the condition it is evident that one or more nosological entities $\mathcal{N}$ have been revealed by the combined use of these two tests of retinal function. Further- N more, the condition may not be rare. From the first 2,00o patients seen in the Electro- N diagnostic Clinic, six had the bilateral acquired form and two the adult unilateral form. An awareness of the existence of the condition will doubtless reveal many more cases.

\section{Summary}

Two cases of unilateral loss of dark adaptation in adult life with no obvious ocular disease

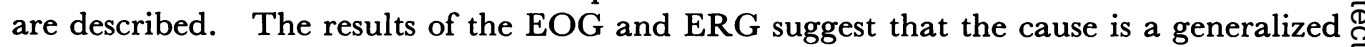
lesion of the bipolar cell layer and that the condition may be reversible. 


\section{References}

ARDEN, G. B. (1968) "Advances in Electrophysiology and -pathology of the Visual System", ed. E. Schmöger, pp. 15-18. Thieme, Leipzig

, Barrada, A., and kelsey, J. H. (1962) Brit. J. Ophthal., 46, 449

and Kelsey, J. H. (1962) J. Physiol. (Lond.), 16r, 205 and WEAle, R. A. (1954) Ibid., 125, 417

armington, J. C., and schwab, G. J. (1954) A.M.A. Arch. Ophthal., 52, 725

AUERBACH, E., GODEL, v., and ROWE, H. (1969) Invest. Ophthal., 8, 332

BARRADA, A., and Kelsey, J. H. (1964) Bull. ophthal. Soc. Egypt, 57, 325

BRown, K. T. (1966) "Retinal Degenerations, ERG, and Optic Pathways", ed. A. Nakajima, pp. 130-140. Maruze, Tokyo

CARR, R. E., RIPPS, H., SIEGEL, I. M., and WEALE, R. A. (1966) Invest. Ophthal., 5, 497

CONE, R. A., and EBREY, T. G. (1965) Nature (Lond.), 206, 913

DOWLING, J. E. (1967) Science, r55, 273

GOURAS, P., and CARR, R. E. (1965) Invest. Ophthal., 4, 3 Io

KARPE, G. (1945) Acta ophthal. (Kbh.), Suppl. 24

KELSEY, J. H., and ARDEN, G. B. (I969) "I.S.C.E.R.G. Symposium, Istanbul". In the press 